\title{
A redescoberta do pensamento de João Calvino para o diálogo ecumênico
}

\author{
Gerson Lourenço Pereira
}

\section{Resumo}

O presente trabalho procura apresentar alguns aspectos do pensamento do Reformador francês João Calvino, buscando situá-lo no contexto atual marcado fortemente pelo pluralismo religioso. A partir da concepção do conhecimento do ser humano de si mesmo e de Deus, o trabalho redescobre o objetivo primordial que conduziu Calvino à elaboração de sua principal obra: Institutio religionis christianae (As Institutas da Religião Cristã). Essa idéia abre caminhos para reconduzir a figura de João Calvino ao debate ecumênico.

Este trabalho é resultado do interesse despertado pelo Reformador João Calvino após a passagem do seu $5^{\circ}$ centenário, ocorrido no ano de 2009, cuja repercussão tímida por parte das demais denominações cristãs, restringiu-se basicamente às igrejas reformadas de tradição herdeiras da teologia calvinista. O que se almeja com esta reflexão é contribuir para o debate ecumênico atual a partir da tradição que procede de João Calvino e de suas elaborações teológicas, não intencionando ser um tratado definitivo, sendo antes um estímulo para ulteriores aprofundamentos.

Palavras-chave: Reforma Protestante, Institutas de Calvino, Teologia Calvinista, Diálogo Ecumênico. 


\begin{abstract}
This paper seeks to present some aspects of the French Reformer John Calvin thought, seeking to situate it in the current context strongly marked by religious pluralism. From the conception of knowledge of the human being of himself and about God, this paper uncovering the primary objective of Calvin that led to the development of his main work: Institutio Christianae religionis (Institutes of the Christian Religion). This idea opens the way to bring the figure of John Calvin in ecumenical debate.

This work result of the interest aroused by the John Calvin Reformer after the completion of its five-hundredth anniversary, occurred in 2009, whose repercussions too timid by the Christian denominations, it was restricted primarily to the churches of the Reformed tradition inherited Calvinist theology. What is with this reflection aims to contribute to the debate from the current ecumenical tradition that stems from John Calvin and his theological elaborations, not intending to be a definitive treatise, but rather a stimulus for further investigations.
\end{abstract}

Keywords: Protestant Reformation, Calvin's Institutes, Calvinist Theology, Ecumenical Dialogue.

\title{
Introdução
}

A proposta desta comunicação é ressaltar alguns aspectos do pensamento do Reformador João Calvino (1509-1564) para o momento atual, marcado fundamentalmente pela pluralidade e diversidade religiosa. $\mathrm{O}$ estímulo para a realização deste trabalho se deve à lembrança do $5^{\circ}$ centenário de Calvino (ocorrido em 2009), cuja repercussão esteve basicamente restrita aos limites das igrejas reformadas, ou seja, das igrejas pertencentes à tradição por ele legada ${ }^{1}$.

\footnotetext{
1 "No dia 10 de julho de 2009 transcorreu o $5^{\circ}$ centenário do nascimento do reformador João Calvino. Os reformados ao redor do mundo promoveram um grande número de eventos especiais para comemorar a data. Na Europa e nos Estados Unidos foram realizadas diversas conferências e exposições históricas. Alguns países lançaram selos postais alusivos ao acontecimento. No Brasil, as principais denominações presbiterianas também se manifestaram. A Igreja Presbiteriana Independente está desenvolvendo extensa programação ao longo do ano. A Universidade Presbiteriana Mackenzie promoveu um encontro referente ao tema com a participação de John Hesselink, uma das maiores autoridades mundiais sobre o personagem. Uma coletânea de cartas de Calvino
} 
O ponto de partida, que será também o fio condutor da presente abordagem, é a idéia do conhecimento do ser humano de Deus e o conhecimento de si mesmo, contida no início da principal obra de Calvino: Institutio religionis christianae (As Institutas da Religião Cristã). Essa idéia concebida e sistematizada perpassa as principais compreensões calvinistas em alguns tópicos doutrinários cristãos, sendo ao mesmo tempo o elemento que possibilita a atualização do pensamento do Reformador e a via para o diálogo ecumênico.

Convém, todavia, apresentar sucintamente quem foi a pessoa de João Calvino.

\section{Quem foi Calvino}

João Calvino nasceu em Noyon, França, em 10 de Julho de 1509. Foi para Paris aos 14 anos, onde estudou gramática, retórica, lógica, aritmética, geometria, astronomia e música. Calvino formou-se em Direito e Literatura. Em 1532 escreveu seu primeiro livro, um comentário à obra De Clementia de Sêneca. Em 1533, na reabertura da Universidade de Paris, escreveu um discurso atacando a teologia dos escolásticos, o que lhe rendeu a perseguição por parte da Igreja de Roma. Não se sabe ao certo, mas foi nesse período (entre 1533 e 1534) que possivelmente Calvino fez sua experiência de conversão.

A partir de 1536, de passagem por Genebra dirigindo-se para Estrasburgo, Calvino se estabeleceu e implantou ali a sua Reforma Protestante. Em Genebra começou a redigir o que é considerada sua obra magna: As Institutas da Religião Cristã. Em 1538 foi expulso de Genebra e viajou para Estrasburgo, onde trabalhou como pastor e professor. Ali se casou com Idelette de Bure. Em 1541 foi convidado a retornar para Genebra onde, em 1559, concluiu, editou e publicou as Institutas. A propósito, ao longo da sua trajetória Calvino escreveu vários tratados, centenas de cartas, e comentários sobre quase todos os livros da Bíblia.

Seu falecimento ocorreu em 27 de Maio de 1564. Calvino morreu com 55 anos de idade. Figura controvertida, que para alguns se revelava com uma imagem tirânica, sem dúvida deixou como grande legado teológico as Insti-

foi lançada pela Editora Cultura Cristã. A Assembleia Legislativa de São Paulo o homenageou em sessão solene. Essas comemorações coincidiram com outra data significativa para os calvinistas brasileiros: os 150 anos da chegada do primeiro missionário presbiteriano, Ashbel Green Simonton. No entanto, fora dos círculos reformados o acontecimento passou quase despercebido." In: MATTOS, Alderi Souza de., "500 anos de João Calvino: pensamentos sobre sua vida e contribuições”, Revista Caminhando v. 14, n. 2, p. 171-179, jul./dez. 2009. P. 172. 
tutas ${ }^{2}$. No seu conteúdo é que se encontram os pontos doutrinários relevantes para o alcance do objetivo proposto nesta reflexão.

\section{A idéia inicial e subjacente nas Institutas: o conhecimento do ser humano de Deus e de si mesmo.}

O luterano Dietrich Korsch ${ }^{3}$, interessado pelo pensamento de Calvino e sua atualização diante do contexto de pluralidade hodierno, é quem auxilia no direcionamento da presente abordagem, uma vez que redescobre como o arcabouço das Institutas a concepção do conhecimento do ser humano de Deus e de si mesmo.

Cabe aqui observar como Calvino introduz o tema. Ele o faz objetivamente no início da sua reflexão:

Quase toda a soma de nosso conhecimento, que de fato se deva julgar como verdadeiro e sólido conhecimento consta de duas partes: o conhecimento de Deus e $o$ conhecimento de nós mesmos. Como, porém, se entrelaçam com muitos elos, não é fácil, entretanto, discernir qual deles precede ao outro, e ao outro origina. ${ }^{4}$

Essa premissa é a perspectiva que esclarece as intenções e formulações do Reformador a respeito dos tópicos relacionados à antropologia teológica, à reali-

\footnotetext{
${ }^{2}$ Sobre as contribuições de Calvino, cf. MATTOS, Alderi Souza de., "500 anos de João Calvino: pensamentos sobre sua vida e contribuições", p. 175-177. Também: WALKER, W., História da Igreja Cristã, vol. 2. ASTE, São Paulo, 1967. PP. 69-80. A respeito da Reforma Protestante e os principais postulados, incluindo os de Calvino, cf. STROHL, Henri., O pensamento da Reforma. ASTE, São Paulo, 2004.

${ }^{3}$ Cf. KORSCH, Dietrich., “Conoscenza di Dio - conoscenza dell'uomo: Alla scoperta dell'idea di fondo dell'Institutio religionis christianae (1559) di Giovanni Calvino", CASSESE, Michele. (Ed.), Alla riscoperta di Giovanni Calvino e Del suo messaggio a cinquecento anni dalla sua nascita. Quaderni de Studi Ecumenici 22 (2011). PP. 73-98.

${ }^{4}$ As Institutas forma inicialmente organizadas e distribuídas em cinco blocos temáticos. $\mathrm{O}$ primeiro é dedicado à Lei, o segundo à Fé, o terceiro à Oração, o quarto aos Sacramentos e o quinto à Liberdade Cristã. Há duas versões em língua portuguesa disponíveis no Brasil. A primeira é uma tradução da versão francesa de 1541 feita por Odayr Oliveti; a outra foi disponibilizada da versão latina de 1559 traduzida por Waldyr Carvalho Luz. Ambas editadas e publicadas pela editora Mundo Cristão. As citações que são feitas neste trabalho correspondem à tradução para o português da edição latina de 1559: CALVINO, João. As Institutas da Religião Cristã (cinco volumes). Tradução Waldyr Carvalho Luz. São Paulo: Cultura Cristã, 2006. As citações não serão feitas por páginas, e sim correspondendo aos volumes, pela divisão dos capítulos e itens com as iniciais da obra. Cf. IRC I, 1-3.
} 
dade divina e à realidade do mundo. Cada um desses tópicos seguirá pontuado no seu respectivo bloco temático conforme a organização do presente trabalho.

\section{Antropologia}

A primeira indagação que a premissa acima acende é de cunho antropológico. O conhecimento do ser humano de si é possível quando o ser humano é posto diante de outro referencial, o referencial divino. Deus, em seu infinito poder criador, é quem ao mesmo tempo toca no coração e na consciência humanas. Portanto, se é intencionado ao homem e à mulher obter um conhecimento verdadeiro de si, deve-se recorrer ao conhecimento de Deus. Ora, tal conhecimento inclui o conhecimento de nós mesmos em meio à natureza (criação) e à sociedade. Em outras palavras, o conhecimento do ser humano de si mesmo, como parte da natureza e em convivência social (em que são consideradas as responsabilidades do ser humano em sociedade), somente é possível quando o humano se posiciona frente a Deus.

Outra pergunta é suscitada: se o conhecimento de si somente é possível ao ser humano quando posicionado diante de Deus, qual é a destinação do homem e da mulher no mundo?

Para Calvino, todo ser humano possui a intransferível vocação de revelar a glória de Deus ${ }^{5}$. Acontece que, ao exercer tal vocação esbarra-se na tendência natural humana de posicionar o conhecimento de Deus a um plano secundário. Essa atitude é dogmaticamente chamada de pecado. Na visão de Calvino, o pecado é a grande contradição da vocação humana.

A fim de restaurar essa vocação, estabelecendo assim uma ponte de reconexão entre Deus e o ser humano, Jesus Cristo é enviado. A ênfase cristológica de Calvino se assenta na perspectiva antropológica ora enunciada. Dessa forma, Cristo é essencialmente concebido como mediador. Corroborando com a tradição dogmática clássica, Calvino afirma a dupla natureza, humanodivina, de Cristo assim manifestada para tornar tal mediação disponível. ${ }^{6}$

A restauração da vocação através da mediação de Jesus Cristo é alcançada pela fé nos seus dois aspectos. O primeiro diz respeito ao ato de crer, consistindo em ouvir e se lançar diante do que é afirmado como novidade de vida. O outro aspecto corresponde à obediência ao que foi estabelecido por Deus e destinado ao ser humano como vocação.

\footnotetext{
${ }^{5}$ IRC I, 5,3.

${ }^{6}$ IRC II, 15, 1-6.
} 
Durante toda a existência humana, a relação entre o conhecimento de si mesmo e de Deus a acompanhará como um processo contínuo. Nesse processo aparece o fenômeno da tentação oriundo da indagação: como, enquanto ser humano, eu posso ter certeza de que a forma de vida que experimento concorda com a fé? Nesse contexto é que as Institutas falam em predestinação. $\mathrm{O}$ sentido procura ser positivo e lógico. A idéia é que nenhum outro, senão Deus, quem pode verificar a correspondência entre a fé e a obediência. O ser humano não é responsável pela conexão entre a fé e a obediência e no bem sucedido propósito do restabelecimento da vocação do homem e da mulher. Quem garante o sucesso é Deus. Através da concepção de eleição a pessoa crente vive esperançosamente na firma certeza do bom êxito de sua fé.

Logicamente se por um lado há pessoas convictamente eleitas, há quem esteja condenada. Todavia, muito embora a lógica proceda, não há quem possa afirmar seguramente que Deus siga o preestabelecido. Em momento algum Calvino ousou imaginar Deus como um déspota que dividiu o mundo entre pessoas eleitas e condenadas. O problema é posto diante de quem acredita na predestinação. Aquele ou aquela que se compreenda como pessoa eleita assim pode se afirmar; não podendo dizer em hipótese alguma que outra pessoa é condenada. ${ }^{7}$

Compreendendo o conhecimento frente ao conhecimento de Deus, o ser humano se autointerpela concluindo que sua vocação é revelar a glória de Deus. Convém, agora, entender como é concebida a idéia da realidade de Deus por Calvino.

\section{Realidade de Deus}

A pergunta de fundo suscitada, quando Calvino aborda o tema do conhecimento de Deus em relação ao conhecimento do ser humano do ser humano de si mesmo, é a seguinte: como é possível compreender a realidade de Deus no mundo? Ou: Como o conhecimento de Deus é alcançado?

Segundo o que Calvino assinala nas Institutas, a Bíblia Sagrada é a guia e a mestra na busca pelo conhecimento de Deus. Ao mesmo tempo em que nela é esclarecido quem é o ser humano, é apresentada a realidade de Deus. Na Bíblia Deus mesmo é quem fala de si, por se tratar não meramente de uma palavra escrita, mas a palavra de Deus comunicada pelo Espírito Santo. ${ }^{8}$ O conhecimento de Deus obtido através da Bíblia manifesta a unidade com o conhecimento do ser

\footnotetext{
${ }^{7}$ IRC III, 24-25.

${ }^{8}$ IRC I, 6-10
} 
humano de si mesmo na vida de fé em que tudo é perpassado e penetrado por tal conhecimento, tanto a corporalidade, como toda a realidade humana. ${ }^{9}$

Para Calvino, Deus é um ser em relação. Na fórmula trinitária, Deus se manifesta em autorelação:

Portanto, aqueles cujo coração tiver sobriedade e que se contentarem com a medida da fé, recebam, em poucas e breves palavras, $o$ que é útil de se conhecer, isto é, quando professamos crer em um só e único Deus, pelo termo Deus entende-se uma essência única e simples, em que compreendemos três pessoas sem especificação, designam-se não menos o Filho e o Espírito que o Pai; quando, porém, o Filho é associado ao Pai, então se interpõe a relação, e com isso fazemos distinção entre as pessoas. Mas, uma vez que as propriedades especificas implicam de si uma gradação nas pessoas, de sorte que no Pai estejam o princípio e a origem, sempre que se faz menção, simultaneamente, do Pai e do Filho, ou do Espírito, se atribui ao Pai, de modo peculiar, o termo Deus. Desse modo retém-se a unidade de essência e tem-se em conta a ordem de gradação, o que, entretanto, nada detrai da divindade do Filho e do Espírito. ${ }^{10}$

Segundo Calvino, não se deve duvidar que Deus é substancial e fundamentalmente um ser em relação. É conhecido através da Bíblia, refletido trinitariamente e em comunhão interna com abertura para a comunhão externa por meio da imanência em Jesus Cristo, já mencionado como o mediador para a reconexão do ser humano com a vocação destinada. Essa realidade relação de Deus é operada no mundo, conforme as concepções que seguem.

\section{Realidade do mundo}

Conforme as preconizações de Calvino, o mundo é a criação de Deus cuja existência é compreendida enquanto a emanação externa de sua riqueza interna. Para Calvino, o mundo é o theatrum gloriae Dei - o teatro da glória de Deus. "Mas não temos vergonha de desprezo a ponto de ter prazer com as obras de Deus que se apresentam aos nossos olhos neste belo teatro do mundo"11.

O mundo é o palco em que é posta em cena a riqueza interior de Deus, sendo a unidade de acontecimentos com um único e coerente sentido: servir à glória de Deus. Nesse sentido se ser do mundo, Deus insere a vida humana. Ele é quem

\footnotetext{
${ }_{9}^{9}$ KORSCH, Dietrich., “Conoscenza di Dio - conoscenza dell'uomo”, p.79-80.

${ }^{10}$ IRC I, 13, 20

${ }^{11}$ IRC I, 14, 20.
} 
estabelece a trama que os atores humanos encenam: a trama da vida em que vivem para a glória de Deus. Deus conhece o que será encenado, sendo os seres humanos atores que colaboram para que o enredo se desenvolva. Esse enredo encenado no mundo de autoria divina é o que a teologia clássica chama de providência.

Como o papel humano é encenado? A autoria do enredo da manifestação da sua glória ressoa como "manipulação de Deus" sobre a liberdade humana? Para Calvino, o ser humano será sempre dotado de autodeterminação e liberdade. Ele não deixa de ser portador de vontades e paixões. Contudo, uma vez que sua vocação é correspondida, sua autodeterminação e liberdades são orientadas como resposta à deliberação do autor do espetáculo: Deus.

Calvino tem em vista sempre a finalidade do que existe. Se o mundo existe, a razão é a manifestação da glória de Deus; se o ser humano existe, é para exercer a vocação de revelar a glória de Deus. Não há, dessa forma, papeis estanques que serão desempenhados individualmente, mas uma trama de inter-relações entre o humano e o divino na busca pela compreensão dessas realidades. Essa foi a motivação que estimulou o Reformador a difundir amplamente as institutas:

Para que possam os leitores auferir maior proveito da presente obra, dir-lhes-ei, em poucas palavras, qual o benefício que lhes advirá do uso deste livro. Porquanto, ao proceder assim, mostrar-lhes-ei qual o propósito ao qual se deverão ater e ao qual dirigir a atenção ao lê-lo. Embora a Santa Escritura contenha uma doutrina perfeita, à qual nada se pode acrescentar, porque aprouve a nosso Senhor nela revelar os infinitos tesouros de sua sabedoria, entretanto a pessoa que não for bastante experimentada em seu manuseio e entendimento necessita de certa orientação e ajuda, para saber o que deva nela buscar a fim de não vaguear incerta, antes alcance rota segura que lhe faculte atingir sempre o fim a que a convoca o Santo Espírito. ${ }^{12}$

Cabe agora, considerando os aspectos refletidos na perspectiva acima assinalada, pontuar algumas vias do pensamento redescoberto de João Calvino para o diálogo ecumênico hoje.

\section{Canal aberto ao diálogo}

Seria equivocado, do ponto de vista histórico e dogmático, afirmar que a ortodoxia calvinista é ecumênica. O pensamento desenvolvido por Calvino foi

${ }^{12}$ Cf. Prefácio à edição francesa de 1541. CALVINO, João. As Institutas da Religião Cristã (cinco volumes). Tradução Waldyr Carvalho Luz. P.45. 
resultado de críticas e oposições sofridas e reagidas que se agravaram depois de sua morte. Mas a intenção deste trabalho não é reforçar os pontos controversos da ortodoxia calvinista, e sim resgatar diretamente do que João Calvino concebeu aspectos que abram caminhos ou, se preferir, que estabeleçam pontes para o diálogo hodierno com o universo plural confessional cristão.

1. A relação integrada entre conhecimento do ser humano de si e de Deus - O pano de fundo de toda a reflexão de Calvino guarda nela mesma uma relevância considerável para o diálogo ecumênico. Conforme a antropologia atual preconiza no que diz respeito à teologia da criação, é parte constitutiva do ser humano a abertura ao transcendente. Interessante é notar que o Reformador Calvino já observava tal abertura ao ponto de afirmar que autoconhecimento humano significava conhecimento de Deus. Neste ponto, em particular, a reflexão teológica de Calvino se abre para concepções Rahnerianas a respeito do componente existencial sobrenatural humano, por exemplo ${ }^{13}$.

2. A vocação humana de revelar a glória divina - Tal dado antropológico abre um caminho importante, sobretudo do ponto de vista teológico-pastoral, entre o pensamento calvinista e outras tradições cristãs. Um forma de o ecumenismo acontecer é através das ações pastorais, convencionalmente consideradas como "ecumenismo prático". Revelar a glória de Deus como resultado do autoconhecimento humano diante de Deus implica no autoreconhecimento como ser responsável no mundo e diante do seu semelhante. O convite a abraçar tal responsabilidade transcende os muros confessionais, fundamentalmente quando, antes mesmo das instituições religiosas, o ser humano de fé é interpelado pelos desafios provenientes de situações, tais como injustiça social, degradação ambiental, arrefecimento da ética. O apelo à responsabilidade é dessa forma universal, é posto diante de quem envereda pelo caminho do conhecimento de Deus e de si mesmo.

3. As Sagradas Escrituras como guia e mestra do conhecimento de Deus - O valor dado à Bíblia como palavra de Deus manifestada pelo Espírito abre uma porta entre as diversas confissões. A Bíblia é a fonte de onde provêm os conceitos fundamentais doutrinários cristãos que, não raro, são motivos de controvérsias e divisões. Contudo, o desafio é estabelecê-la como "a Palavra

${ }^{13}$ Cf. RAHNER, Karl, Curso Fundamental da Fé. 3ºed. São Paulo: Paulus, 2004. 
do Deus do povo e Palavra do Povo de Deus". Não eximindo do compromisso exegético, a Bíblia deve ser também lida com a ótica pastoral e ecumênica, como o critério de julgamento para lidar com os desafios acima assinalados. É fundamental destacá-la como meio e fim do diálogo.

4. Deus como ser em relação - A abordagem de Calvino sobre a realidade de Deus oferece um tom de pessoalidade na economia trinitária, bem como relação com a pessoa crente. Essa pessoalidade poderia, pela via da experiência, possibilitar manifestações eclesiais de profunda comunhão em resposta ao individualismo e intimismo da fé, que são recorrentes no contexto atual.

5. A realidade do mundo como o teatro da glória de Deus - Contemplar o mundo como o teatro onde o enredo da vida é encenado recorda a responsabilidade ética de todo povo de Deus. É profundamente desafiador recuperar a o papel humano a ser desempenhado no mundo, o que poderia redundar em implicações concretas no que se refere ao arco de ação pastoral por parte de todos os cristãos.

\section{Conclusão}

Mesmo que tardiamente, é sempre oportuna a tentativa de atualizar o pensamento dos ícones do Cristianismo. Ainda que historicamente se possam alimentar rechaços, repúdio e oposições o diálogo ecumênico se propõe a superar barreiras, abrir caminhos e construir pontes.

O que se espera com o fim desta reflexão é que a perspectiva de Calvino no que diz respeito aos temas apresentados provoque os corações de boa vontade a caminhar na direção da construção de uma sociedade mais tolerante, unida e solidária. Disso, em parte, depende da ação interrelacionada do povo de Deus.

\section{Referências Bibliográficas}

CALVINO, João. As Institutas da Religião Cristã (cinco volumes). Tradução de Waldyr Carvalho Luz. São Paulo: Cultura Cristã, 2006.

KORSCH, Dietrich., "Conoscenza di Dio - conoscenza dell'uomo: Alla scoperta dell'idea di fondo dell'Institutio religionis christianae (1559) di Giovanni Calvino", CASSESE, Michele. (Ed.), Alla riscoperta di Giovanni Calvino 
e Del suo messaggio a cinquecento anni dalla sua nascita. Quaderni de Studi Ecumenici 22 (2011). PP. 73-98.

MATTOS, Alderi Souza de., "500 anos de João Calvino: pensamentos sobre sua vida e contribuições”, Revista Caminhando v. 14, n. 2, p. 171-179, jul./dez. 2009.

RAHNER, Karl, Curso Fundamental da Fé. $3^{\circ}$ ed. São Paulo: Paulus, 2004.

STROHL, Henri, O pensamento da Reforma. ASTE, São Paulo, 2004.

WALKER, W., História da Igreja Cristã, vol. 2. ASTE, São Paulo, 1967.

Gerson Lourenço Pereira

Doutorando em Teologia Sistemático-Pastoral na PUC-Rio.

Pastor metodista e professor de Teologia Sistemática e Prática em instituições dedicadas ao ensino teológico da

Igreja metodista no Rio de Janeiro.

Artigo Recebido em 18/08/2011

Artigo Aprovado em 21/11/2011 